\title{
A construção do outro nas redes sociais: uma análise semiolinguística de comunidades do Facebook
}

\author{
The construction of the other ones in social networks: a \\ semiolinguistics analysis of facebook communities
}

Paula Crespo Halfed*

RESUMO: No presente trabalho temos como objetivo examinar o modo de construção da imagem do outro nas tramas da internet, a partir do exame da encenação discursiva produzida em textos extraídos de duas comunidades da rede social Facebook, relacionadas ao tema "religião": a comunidade Igreja Apocalíptica do Oitavo Dia e a comunidade $A T E A$. Sob o quadro teórico-metodológico da Semiolinguística do discurso, o trabalho focalizará os procedimentos e estratégias empregados nos textos para a produção de determinados efeitos de sentido, considerando o contrato comunicativo firmado entre os interlocutores.

PALAVRAS-CHAVE: Encenação. Ironia. Contrato. Cenografia. Semiolinguística.

ABSTRACT: This paper aims to examine how to construct he imagem of the other ones in the internet, form the examination of texts produced in discourse scenario drawn from two communities in the social network Facebook, on the theme "religion": Igreja Apocalíptica do Oitavo Dia comunnity and ATEA community. Under the theoretical and metodological semiolinguistics of discourse, the paper will focus on procedures and strategies employed in the texts for the production of certain efects, considering the contract firmed between the interlocutors.

KEYWORDS: Staging. Irony. Contract. Scenografy. Semiolinguistics.

\footnotetext{
* Doutoranda em Língua Portuguesa pelo Departamento de Letras Vernáculas da Faculdade de Letras da Universidade Federal do Rio de Janeiro (UFRJ). E-mail: paula.halfeld@gmail.com
} 


\section{Introdução}

A relação linguagem/preconceito pode ser analisada sob diversas perspectivas, desde as que atentam para o preconceito linguístico proveniente da existência de uma norma padrão que sobrepuja as demais, até as que focalizam o modo como os sujeitos sociais criam imagens do outro em seus discursos a partir de um sistema de estereótipos vigente em dada sociedade. É sob este último ângulo que o presente trabalho objetiva examinar os procedimentos e estratégias empregados por usuários de duas comunidades da rede social Facebook na construção da imagem do outro, bem como os efeitos de sentido produzidos em seus textos.

Para fundamentar a análise, seguimos os postulados teóricos da Semiolinguística do discurso, no que tange ao ato de linguagem, aos quatro sujeitos que o integram e ao contrato de comunicação firmado entre os interlocutores.

Em um primeiro momento, são apresentados alguns dos principais postulados da Teoria de Patrick Charaudeau e algumas considerações sobre os conceitos de cena de enunciação e encenação, fundamentais para as observações presentes neste artigo. Em seguida, são descritos o corpus que compõe a pesquisa e a metodologia de análise dos dados. Por fim, são apresentados os resultados do trabalho proposto, com o exame específico de cada texto selecionado, focalizando os efeitos de sentido produzidos e as estratégias discursivas usadas para tal.

\section{A teoria semiolinguística}

Teoria desenvolvida na década de 1970 pelo francês Patrick Charaudeau, a Semiolinguística do discurso tem como pressuposto o fato de que o ato de linguagem não pode ser analisado apenas do ponto de vista de sua configuração verbal, mas também e, sobretudo, como parte de um jogo em que o sujeito falante encena sua participação de modo a produzir determinados 
efeitos de sentido. Dessa forma, tal configuração verbal deve ser examinada também no que se refere a seu aspecto implícito. Seguindo esses postulados, uma análise semiolinguística estuda "o que" fala a linguagem, em termos de representação do mundo, a partir do "como" se fala, ou seja, considerando as situações de comunicação em que os discursos se inscrevem, bem como as restrições e a margem de manobra determinados pelo contrato de comunicação firmado entre os interlocutores.

Entende-se por "situação de comunicação" o ambiente físico e social do ato de comunicação, "o quadro de referência ao qual se reportam os membros de uma comunidade social quando se comunicam" (CHARAUDEAU, 2009a, p.67). Já por "contrato comunicativo" entende-se o conjunto de restrições estabelecidas pelas práticas sociais, instauradas por indivíduos que buscam viver em comunidade e ratificadas pelos discursos que subjazem a uma dada sociedade. O locutor de um ato de linguagem deve se submeter a tais restrições e supor que seu destinatário também partilhe das mesmas regras de modo que a comunicação seja bem sucedida.

Para Charaudeau (2009b), o ato de linguagem constitui um jogo no qual encenam quatro sujeitos inscritos em dois espaços distintos: (a) um espaço "externo", de fala, no qual se encontram um EU comunicante (EUc) e um TU interpretante (TUi), responsáveis, respectivamente, pela produção e pela interpretação do ato de linguagem, e (b) um espaço "interno", de discurso, no qual se encontram um EU enunciador (EUe) - que não necessariamente condiz com o sujeito externo - instaurador, por sua vez, de um TU destinatário (TUd) a quem se dirige. Nesses dois circuitos, o EUc lança mão de uma série de estratégias, permitidas pelo contrato de comunicação que rege $o$ ato, para levar o TUi a se identificar com o TUd e, assim, alcançar seus objetivos comunicativos.

É em virtude desse jogo de restrições e estratégias que Charaudeau (2009b) compara a produção de um ato de linguagem a uma "expedição" e a uma "aventura". "Expedição" por se tratar de um projeto de fala de um sujeito comunicante, que objetiva produzir certos efeitos de sentido. "Aventura" 
porque o TUi pode não se identificar com o TUd, fazendo com que o EUc não obtenha os efeitos pretendidos em seu ato comunicativo. O TUi pode não dominar os efeitos produzidos ou o EUc pode deixar transparecer efeitos não previstos, o que pode ser motivado pelas particularidades das experiências individuais e dos saberes que cada indivíduo detém. $\mathrm{O}$ ato de linguagem assemelha-se, assim, a uma aposta. No caso ilustrativo da produção da ironia, os sujeitos do ato de linguagem se comportam da seguinte maneira:

EUe $\operatorname{diz} p>$ EUc sabe (ou pensa) não- $p>$ EUc pretende que o TUi se identifique com um TUd que acredita que EUc não pensa $p$.

Em sua tarefa de interpretar um enunciado, o TUi deve criar uma série de hipóteses sobre: (a) o saber do enunciador, (b) seus pontos de vista em relação a seus enunciados e (c) seus pontos de vista em relação ao sujeito destinatário. Interpretar é, assim, um trabalho de suposição de uma intenção comunicativa.

Ao analista do discurso cabe, portanto, depreender as significações possíveis de um enunciado, que surgem da confluência dos processos de produção e interpretação. Não deve pretender analisar apenas o ponto de vista do sujeito comunicante nem apenas o ponto de vista do sujeito interpretante:

O sujeito analisante está em posição de coletor de pontos de vista interpretativos e, por meio da comparação, deve extrair constantes e variáveis do processo analisado. A pergunta 'Quem fala?' deve ser substituída pela pergunta "Quem o texto faz falar?" (CHARAUDEAU, 2009b, p.63).

Desse modo, as análises empreendidas neste artigo são norteadas pelo pressuposto de que 0 ato de linguagem se constrói na confluência de imagens de quatro sujeitos, que se instauram segundo as restrições e estratégias previstas em um contrato comunicativo específico e dentro de uma situação de comunicação também específica. Nossa tarefa, enquanto analistas do discurso, será, portanto, a de identificar, com base nesses pressupostos, algumas 
possíveis interpretações para os textos selecionados e os procedimentos e estratégias empregados para tal.

\section{Cena de enunciação e encenação}

A noção de cena de enunciação é atribuída a Dominique Maingueneau, que a define em consonância com a noção de ethos discursivo (a imagem de si construída no interior do próprio discurso). A cena de enunciação, segundo o autor, está intimamente ligada ao tipo e ao gênero discursivo e consiste na representação, na colocação em cena da enunciação - entendida como o ato de produção de um enunciado, pressupondo, necessariamente, um locutor e um destinatário.

Desse modo, Maingueneau (2008) assevera que a cena de enunciação se desdobra em: (a) cena englobante, relativa ao tipo de discurso (discurso politico, científico, propagandista, religioso, etc.); (b) cena genérica, relativa ao gênero de discurso (gênero panfleto, artigo, manifesto, etc.), e (c) cenografia, definida como a inscrição em uma cena, a partir da atribuição de determinados lugares no discurso (como lugar de beleza, de juventude - próprios do discurso publicitário -, da ética - próprio do discurso político - dentre outros).

A cenografia é um quadro e, ao mesmo tempo, um processo; ela legitima o enunciado e é por ele legitimada, uma vez que deve parecer ser a cenografia mais apropriada àquela ocasião específica. Um político que discursa para uma classe de operários, por exemplo, pode assumir uma cenografia de "homem do povo", caso queira estabelecer uma relação de proximidade com seu público e, assim, conquistar sua adesão. As variações na cenografia são determinadas, sobretudo, pelos gêneros. Há gêneros que não exigem cenografia (como os gêneros utilitários, por exemplo) e há outros que admitem várias cenografias, a depender dos objetivos do enunciador (como os textos de propaganda, que mobilizam diversas cenografias de modo a conquistar seus potenciais consumidores). 
No interior da cena de enunciação se desenvolve a encenação, definida pelo conjunto de papéis atribuídos ao sujeito falante e a seu destinatário, dentro de um espaço de restrições e de manobra previsto pelo contrato comunicativo e pela situação de comunicação (CHARAUDEAU, 2009b). Segundo Charaudeau (2009b), o sujeito falante se apropria de categorias de línguas (elementos linguísticos), organizados segundo determinados modos de organização discursivos (narrativo, descritivo, argumentativo), para, a partir daí, encenar seu discurso. Nesse processo de encenação, o sujeito emprega componentes e procedimentos específicos com o fim de produzir efeitos de sentido, conforme já assinalado anteriormente. É pautado nessas noções que o presente trabalho pretende pôr em prática sua proposta de análise.

\section{Corpus e Metodologia}

O corpus utilizado neste trabalho é composto por oito textos extraídos de duas comunidades da rede social Facebook: comunidade Igreja Apocalíptica do Oitavo Dia e comunidade ATEA.

A comunidade Igreja Apocalíptica do Oitavo Dia é caracterizada por assumir a voz de uma igreja evangélica para, de forma irônica e satírica, rechaçar esse discurso, criticando e ridicularizando as agremiações religiosas desse tipo.

A comunidade ATEA tem a finalidade de reunir ateus do Brasil na luta pela construção de um Estado totalmente laico. Seus membros ocasionalmente organizam eventos e manifestações pela defesa dos ateus e contra influências de correntes religiosas no espaço público.

Para realizar a pesquisa proposta foram selecionados quatro textos publicados em cada página dessas comunidades no Facebook, totalizando oito publicações. Seguindo a tendência da escrita virtual, caracterizada pela grande quantidade de textos múltiplos (que conjugam linguagem verbal e não-verbal), 
a maioria dos textos escolhidos utilizam imagens para apoiar, complementar ou mesmo justificar a parte verbal.

A metodologia adotada na análise segue os postulados de uma análise do discurso semiolinguística, focalizando o modo como são empregados determinados recursos linguísticos e discursivos para a produção de efeitos de sentido específicos. A análise levará em consideração o esquema de quatro sujeitos do ato de linguagem proposto por Charaudeau (2009b) e o contrato de comunicação estabelecido entre as comunidades (enquanto instâncias enunciadoras) e seu público-leitor.

\section{A comunidade Igreja Apocalíptica do Oitavo Dia}

Com base no esquema proposto por Charaudeau (2009b) para o ato de linguagem, o EU comunicante dos primeiros quatro textos apresentados a seguir é a comunidade Igreja Apocalíptica do Oitavo Dia, que, conforme já apontado anteriormente, é formada por membros que se apropriam de um discurso supostamente evangélico como modo de criticar e rechaçar esse discurso, a partir do uso de certas estratégias. Trata-se, assim, de um exemplo de encenação no sentido mais literal do termo. Na própria descrição da comunidade, a ironia já pode ser percebida no paradoxo "colaboração voluntária obrigatória", sugerindo que a finalidade da igreja é meramente lucrativa:

Esta igreja foi fundada para atender a necessidade soberana de Deus de implantar um sistema único de salvação. Apesar de existirem diversas igrejas atualmente, somente aqui você encontrará a salvação através da colaboração voluntária obrigatória de dízimos $(. . .)^{1}$

Na figura 1, há uma cenografia própria de um texto propagandístico, com forte apelo ao público destinatário. O uso de frases de efeito como "Mega

\footnotetext{
${ }^{1}$ Disponível em: <https://www.facebook.com/IgrejaApocaliptica>. Acesso em: 14 abr. 2012 (grifos nossos).
} 
promoção!" em letras garrafais, o destaque dado ao preço do produto através de um balão de cor forte, o tamanho da foto do produto (ocupando metade do "anúncio"), o uso do discurso de autoridade com o depoimento de uma suposta consumidora do produto são estratégias de que o enunciador se vale para imitar um texto publicitário.

Entretanto, a ironia que permeia o texto transparece na própria essência do produto oferecido: trata-se, segundo o anúncio, do suor do pastor Valdemiro - um pastor famoso de uma agremiação religiosa evangélica. $O$ texto que sucede à foto do produto deixa claro o propósito irônico do sujeito comunicante: a atribuição absurda de caráter sagrado ao suor do pastor e a relação das utilidades também absurdas do produto, seguindo os moldes da propaganda ("ideal para temperar saladas, banhar as genitálias, usar como repelente de exús, etc."), revelam a finalidade humorística do texto, que beira o escracho.

Acompanhando a relação entre os quatro sujeitos do ato de linguagem, o EUc deste texto responde pela construção de um EUe, que crê na propaganda do suor bento do apóstolo Valdemiro. O EUc, com o uso dos procedimentos e estratégias descritas acima, espera que o TUi (sujeito externo) se identifique com o TUd (sujeito do discurso, instaurado pelo EUe), que acredita que EUc pensa o oposto do EUe, ou seja, não acredita na propaganda, tendo consciência do caráter absurdo de sua oferta. 


\section{MEGA PROMOÇÃO!} SUOR BENTO DO APÓSTOLO VALDEMIRO

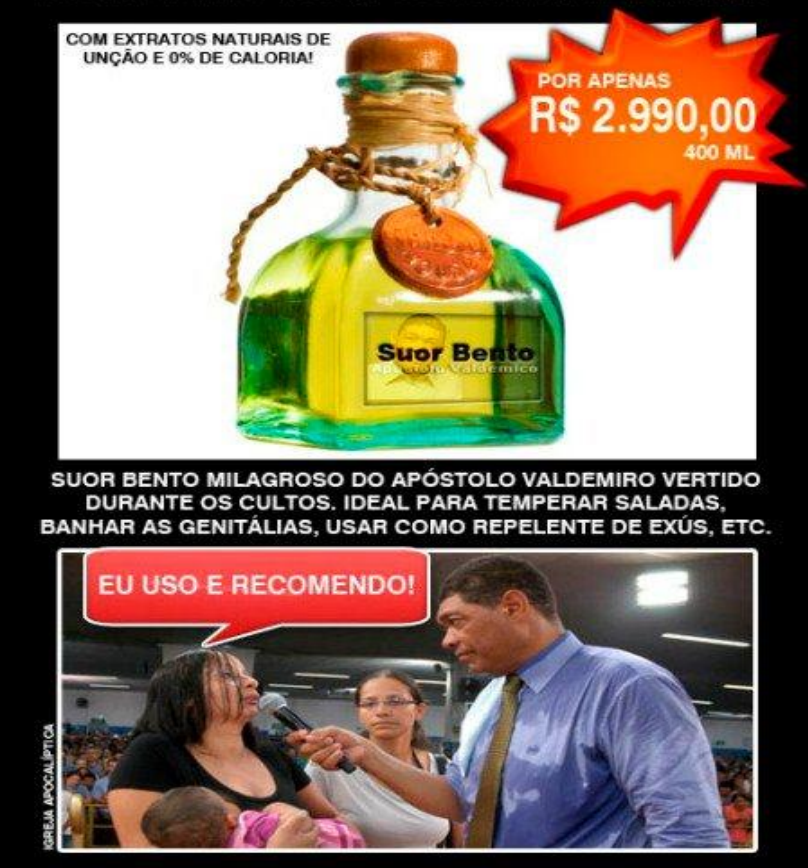

Figura 1: Texto extraído da comunidade Igreja Apocalíptica do Oitavo Dia ${ }^{2}$

O mesmo se aplica ao texto a seguir, também pautado pela ironia. Há uma proposta de imitação de um jogo típico de jornais impressos ("Jogo dos Sete Erros"), em que o participante deve identificar sete distinções entre duas figuras bastante semelhantes.

Essa encenação do jogo, na verdade, tem o propósito de ressaltar a ausência de diferenças significativas entre as duas figuras, que mostram, a primeira, um grupo de roqueiros (cuja denominação "Led Zé Pelinho" faz referência à banda de rock "Led Zeppeling"), e a segunda, um grupo musical do gênero pop formado por mulheres ("Banana Split"). Ao cumprir uma finalidade inversa da original, o jogo dos sete erros, neste caso, acentua ironicamente uma suposta aproximação entre duas bandas de estilos aparentemente opostos (rock X pop). Isso funciona como argumento para justificar o "slogan" de protesto que finaliza o texto: "Diga não ao roque!" (os erros de grafia reforçam

\footnotetext{
${ }^{2}$ Disponível em: <https://www.facebook.com/IgrejaApocaliptica?ref=ts>. Acesso em: 12 abr. 2012.
} 
o caráter satírico e debochado da comunidade, que, de maneira irônica, critica e ridiculariza o discurso evangélico).

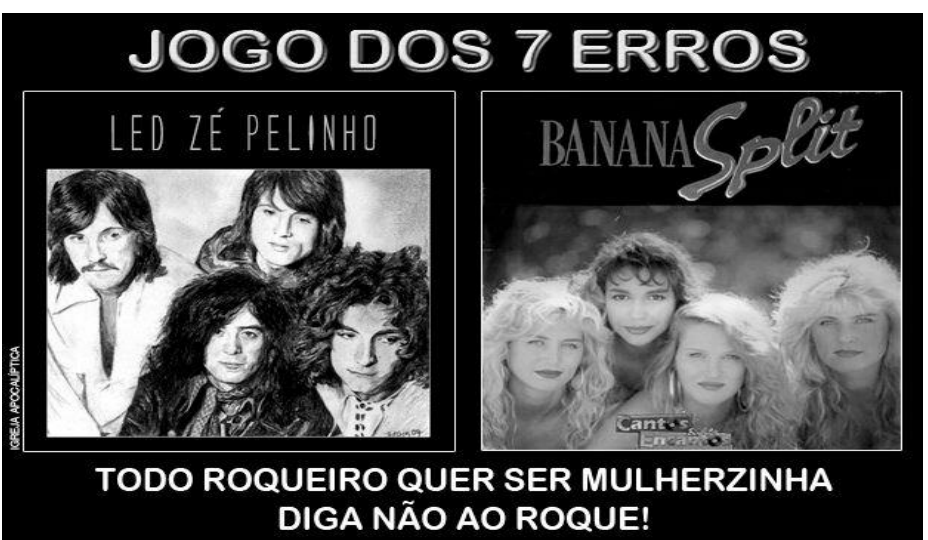

Figura 2: Texto extraído da comunidade Igreja Apocalíptica do Oitavo Dia $^{3}$

Na figura 3, extraída da comunidade em questão, o sujeito emprega 0 procedimento da composição classificatória, caracterizada pela apresentação de diferentes argumentos em forma de listas, inventários, quadros ou figuras. 0 procedimento foi utilizado de modo a embasar uma comparação por dessemelhança entre os roqueiros e os evangélicos. As imagens contidas no texto também auxiliam no estabelecimento das distinções, de modo a depreciar os roqueiros e a valorizar os evangélicos.

O grupo dos roqueiros é representado, na figura, por dois sujeitos em um ambiente hostil, sem cor, no qual invertem uma cruz para sinalizar sua rejeição a valores cristãos. O grupo dos evangélicos, por sua vez, é representado por uma cantora gospel, em um cenário colorido, iluminado, sugerindo que o meio dos evangélicos é um meio de luz e de vida, em oposiçã à obscuridade da primeira imagem.

${ }^{3}$ Disponível em: <https://www.facebook.com/IgrejaApocaliptica?ref=ts>. Acesso em 12 abr. 2012. 


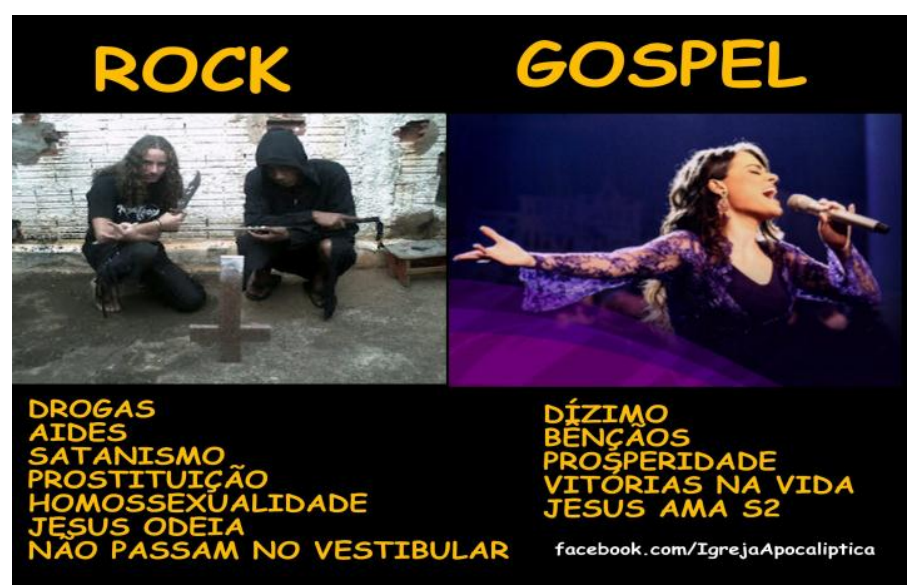

Figura 3: Texto extraído da comunidade Igreja Apocalíptica do Oitavo Dia ${ }^{4}$

O recurso da composição classificatória também foi usado no texto abaixo (figura 4), em que é apresentada uma lista de supostos serviços oferecidos pela Igreja a seus "clientes", com os respectivos valores. A estruturação do texto como lista atende ao propósito de ressaltar a finalidade essencialmente comercial que, como insinuado pelo texto, subjaz aos fundamentos das igrejas evangélicas. A categorização de clientes simulada pela lista e típica de empresas como cartões de crédito, companhias aéreas, dentre outras (cliente "Platinum", "Gold" e "Premium") também atende a este projeto de fala.

\footnotetext{
${ }^{4}$ Disponível em: <https://www.facebook.com/IgrejaApocaliptica?ref=ts>. Acesso em 12 abr. 2012.
} 


\begin{tabular}{|c|c|c|c|}
\hline SERVICCO & PLATINUM & GOLD & PREMIUM \\
\hline $\begin{array}{l}\text { Antecedentes de } \\
\text { Pecados }\end{array}$ & 800,00 & 720,00 & 650,00 \\
\hline Análise Espiritual & 777,00 & 671,00 & 590,00 \\
\hline $\begin{array}{l}\text { Balde de Água } \\
\text { Benta }\end{array}$ & 31,00 & 24,00 & 16,00 \\
\hline $\begin{array}{l}\text { Batismo na Piscina } \\
\text { Sagrada }\end{array}$ & 847,00 & 637,00 & 489,00 \\
\hline Benção via Twistter & 14,00 & 7,00 & GRÁTIS \\
\hline Benção via Emeil & 29,00 & 21,00 & 14,00 \\
\hline Bíblia Sagrada & 281,00 & 218,00 & 164,00 \\
\hline $\begin{array}{l}\text { Celebraçáa de } \\
\text { Casamento }\end{array}$ & $5.400,00$ & $4.100,00$ & $3.500,00$ \\
\hline $\begin{array}{l}\text { Certificado de } \\
\text { Castidade }\end{array}$ & $1.800,00$ & $1.200,00$ & 900,00 \\
\hline Chicote Bento & 327,00 & 254,00 & 189,00 \\
\hline Cinto de Castidade & 139,00 & 96,00 & 76,00 \\
\hline $\begin{array}{l}\text { Cutucada Santa no } \\
\text { Facebook }\end{array}$ & 79,00 & 32,00 & 19,00 \\
\hline $\begin{array}{l}\text { Desencapetamento } \\
\text { na Igreja }\end{array}$ & 539,00 & 401,00 & 322,00 \\
\hline $\begin{array}{l}\text { Desencapetamento } \\
\text { Delivery }\end{array}$ & 992,00 & 812,00 & 660,00 \\
\hline Diploma de Dizimista & 49.00 & 38,10 & 29,00 \\
\hline Imersão do Nome no & 87,00 & 64,00 & GRÁTIS \\
\hline $\begin{array}{l}\text { Óleo Ungido ( } 2 \\
\text { litros) }\end{array}$ & 534,00 & 437,00 & 362,00 \\
\hline Pastor Delivery & 694,00 & 548,00 & 429,00 \\
\hline Terapia do Joelhaço & 769,00 & 620,00 & 485,00 \\
\hline $\begin{array}{l}\text { Unção da Cajadada } \\
\text { de Moisés }\end{array}$ & 412,00 & 359,00 & 287,00 \\
\hline $\begin{array}{l}\text { Unção da Enxadada } \\
\text { Santa }\end{array}$ & 310,00 & 250,00 & 178,00 \\
\hline $\begin{array}{l}\text { Unção das Pedradas } \\
\text { de Jerusalém }\end{array}$ & 214,00 & 169,00 & 112,00 \\
\hline Unção dos Enfermos & $2.590,00$ & $1.820,00$ & $1.104,00$ \\
\hline Vale-Pe & 600,00 & 520,0 & 450,00 \\
\hline
\end{tabular}

Figura 4: Texto extraído da comunidade Igreja Apocalíptica do Oitavo Dia ${ }^{5}$

Com a análise dos textos selecionados, pode-se observar que o emprego da ironia na comunidade Igreja Apocalíptica do Oitavo Dia se realiza em uma dimensão dupla: tanto no interior do discurso de cada texto, como no discurso fundador da própria comunidade, ele mesmo essencialmente irônico por se apropriar do discurso evangélico com o fim de negá-lo.

\section{A comunidade ATEA:}

O EU comunicante na comunidade ATEA destila críticas a instituições religiosas de caráter geral, sem especificar as agremiações - o que se justifica pelo fundamento da não-crença e da negação a qualquer religião entre os membros da comunidade. Por se tratar de uma comunidade aberta, o TU destinatário pode ser tanto um integrante da comunidade como qualquer

\footnotetext{
${ }^{5}$ Disponível em: <https://www.facebook.com/IgrejaApocaliptica?ref=ts>. Acesso em 12 abr. 2012.
} 
usuário da rede social Facebook que acesse sua página, a exemplo da comunidade Igreja Apocalíptica do Oitavo Dia, também aberta.

No primeiro texto escolhido (figura 5), emprega-se o procedimento discursivo da comparação para ressaltar uma semelhança entre as duas figuras mostradas. O texto faz alusão a uma personagem de uma série de TV mexicana muito famosa entre jovens brasileiros (Chaves), considerada pelas personagens infantis da série uma bruxa que frequentemente estabelecia contato com o satanás. A aproximação entre esta personagem humorística - presente na TV brasileira por mais de 30 anos - e o Bispo Macedo - uma autoridade da Igreja Universal do Reino de Deus - é responsável pelo tom humorístico que recobre o texto, ridicularizando a empreitada do Bispo e destacando o caráter improvável do sucesso da busca na qual se empenha: a procura do satanás.

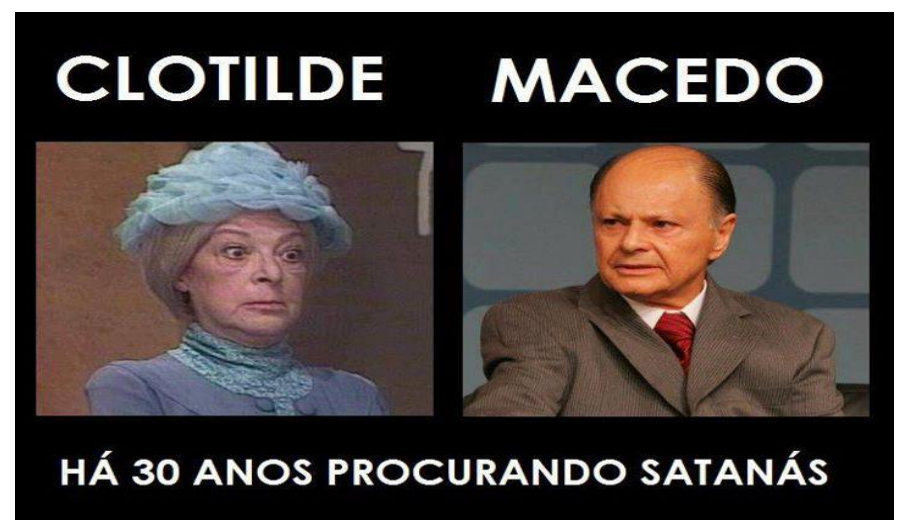

Figura 5: Texto extraído da comunidade ATEA ${ }^{6}$

O próximo texto extraído da comunidade ATEA, diferente dos demais textos apresentados até então, não emprega elementos não-verbais, como figuras e imagens. O texto, representado na figura 6, é baseado em um questionamento cuja visada é negar um argumento usado pelas igrejas para justificar a necessidade de fé: o de que Deus joga sua ira sobre os descrentes. Seguindo esse propósito, utiliza também uma citação direta do livro mais sagrado entre os cristãos (Bíblia), cuja credibilidade e legitimidade são

\footnotetext{
${ }^{6}$ Disponível em: <https://www.facebook.com/ATEA.ORG.BR?ref=ts>. Acesso em: 12 abr. 2012.
} 
aparentemente inquestionáveis, de modo a comprovar a atitude ameaçadora e coerciva da igreja na conquista de fiéis.

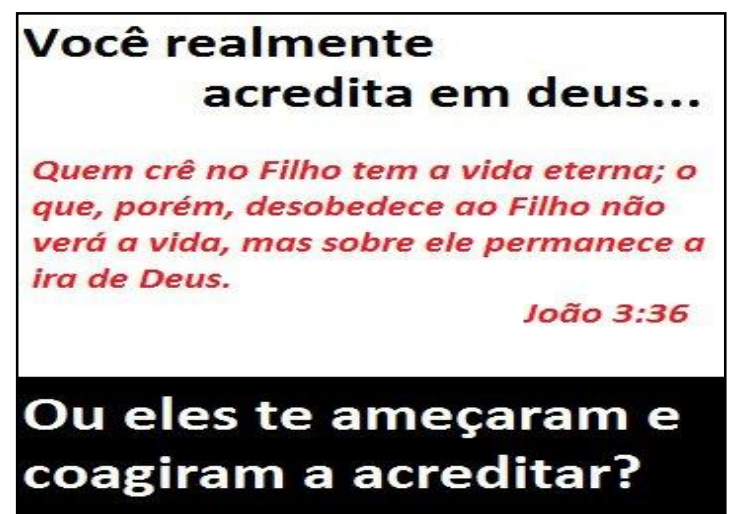

Figura 6: Texto extraído da comunidade ATEA $^{7}$

O texto que segue (figura 7) reproduz o gênero "tirinha", com a utilização dos memes ("carinhas" padronizadas, bastante usadas nas redes sociais para a montagem de tirinhas humorísticas pelos próprios usuários das redes).

O texto é construído com base em uma suposta gradação no nível de periculosidade de bandidos, indo do iniciante (assaltante comum), passando pelo intermediário (político), chegando ao avançado/profissional (pastor). 0 objetivo da tirinha, portanto, é o de denunciar a prática de alguns pastores que cobram altos dízimos a seus fiéis e que, em virtude disso, enquadram-se, segundo o texto, no mais alto nível de "especialização" dentro da classe de bandidos.

A quebra de expectativa gerada com o enquadramento do religioso na categoria de bandido da mais alta periculosidade responde pelo humor da tirinha, condizente com o asseverado por Valente (2010, p.171), segundo o qual a quebra de expectativa constitui "um traço inconfundível de expressivas construções humorísticas".

\footnotetext{
${ }^{7}$ Disponível em: <https://www.facebook.com/ATEA.ORG.BR?ref=ts>. Acesso em: 12 abr. 2012.
} 
O erro na pluralização da palavra "irmão" atende ao objetivo de ridicularizar os pastores das igrejas evangélicas, sugerindo uma suposta falta de instrução desses religiosos; falta essa conflitante com a função de orador.

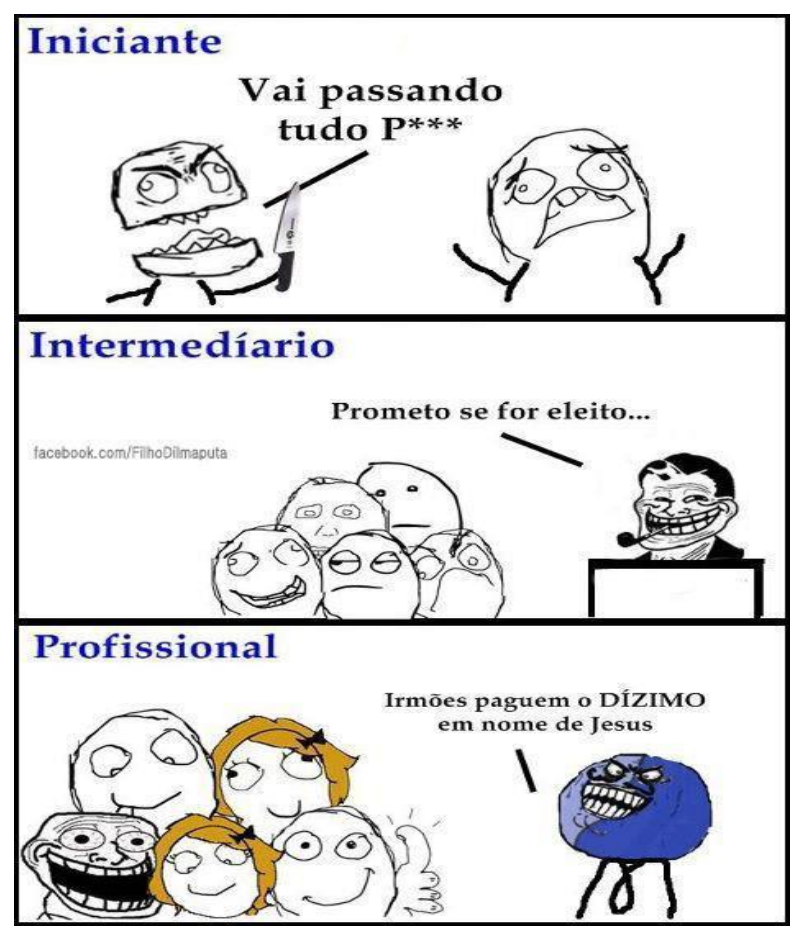

Figura 7: Texto extraído da comunidade ATEA $^{8}$

No quinto e último texto desta comunidade, apresentado na figura 8 , o tom humorístico que permeou os demais textos dá lugar a um discurso mais sério e acusativo, cujo propósito é criticar a "hipocrisia ocidental", por meio da denúncia ao preconceito contra algumas religiões orientais.

As imagens são essenciais para complementar o texto escrito, que se constrói a partir da atribuição de valores a cada religião de acordo com a percepção/ponto de vista da sociedade ocidental. Os termos que recebem significação positiva na cultura ocidental, atribuídos às judias e às freiras católicas/ortodoxas, são contrapostos ao valor negativo atribuído à mulher muçulmana. O procedimento discursivo da comparação por dessemelhança, portanto, sustenta a construção da denúncia.

\footnotetext{
${ }^{8}$ Disponível em: <https://www.facebook.com/ATEA.ORG.BR?ref=ts>. Acesso em: 12 abr. 2012.
} 


\section{Hipocrisia Ocidental...}

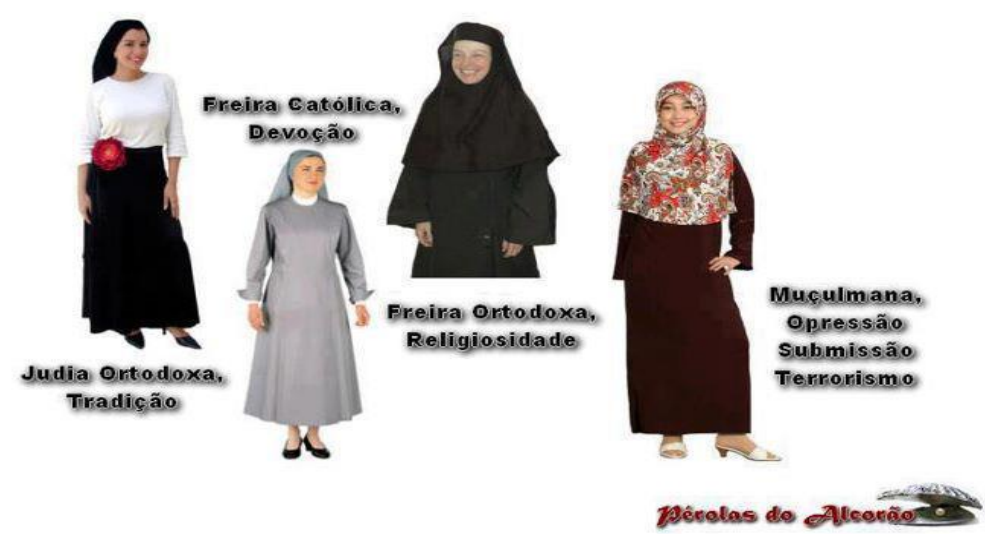

Figura 8: Texto extraído da comunidade ATEA $^{9}$

\section{Considerações finais}

Com o exame dos textos extraídos das comunidades virtuais Igreja Apocalíptica do Oitavo Dia e ATEA, foi possível verificar que em ambas as comunidades, há uma representação do outro de forma estereotipada, generalizada, que se constrói no uso de procedimentos e estratégias discursivas. A construção de imagens negativas do outro nessas comunidades tem como base, principalmente, um discurso irônico e, por vezes, humorístico. Os procedimentos empregados e os efeitos de sentido produzidos apontam, salvo algumas exceções, para uma "brincadeira", para o lúdico, a despeito da seriedade das acusações.

Foi observado também que as diversas formas de colocação em cena do discurso (encenação) refletem a variedade de cenografias construídas nessas produções textuais: cenografia de um locutor que quer vender um produto, cenografia de um religioso que pré-julga um roqueiro, cenografia de alguém que enxerga a hipocrisia da sociedade e a denuncia, dentre outras.

\footnotetext{
${ }^{9}$ Disponível em: <https://www.facebook.com/ATEA.ORG.BR?ref=ts>. Acesso em: 12 abr. 2012.
} 
A diversidade de cenografias e o caráter lúdico dessas produções textuais só são possíveis porque o contrato comunicativo estabelecido entre os sujeitos do ato de linguagem nas redes sociais o permite. Como o Facebook é uma rede social que prioriza a interação entre amigos, permitindo, portanto, um contato mais informal, é comum que seus membros compartilhem informações engraçadas e que façam brincadeiras entre si, o que justifica a publicação de textos como os analisados neste trabalho.

No que tange à situação de comunicação, verificou-se a importância dos conhecimentos partilhados pelos interlocutores para o sucesso da compreensão e da visada de persuasão dos textos. Em algumas publicações selecionadas, é necessário, por exemplo, que o sujeito interpretante saiba que algumas igrejas possuem características comerciais, que algumas delas frequentemente fazem alusão ao satanás, que existiu uma banda de rock chamada Led Zeppelin e uma banda pop chamada Banana Split, quem é a personagem Dona Clotilde, quem é - Bispo Macedo etc. Isso comprova a pertinência do quadro teóricometodológico da semiolinguística: o estudo da construção do sentido a partir de procedimentos e estratégicas linguístico-discursivos, considerando a situação de comunicação, o contrato firmado entre os sujeitos e os conhecimentos por eles partilhados.

Por fim, foi possível constatar, mais uma vez, que a linguagem, enquanto forma de agir socialmente, resguarda os pré-julgamentos que norteiam as sociedades e os materializa de diversas maneiras. A representação do outro nas redes sociais através de procedimentos e estratégias discursivos é, como visto neste trabalho, um exemplo dessa articulação entre linguagem e preconceito.

\section{Referências}

ATEA (Associação Brasileira de Ateus e Agnósticos). Disponível em: <https://www.facebook.com/ATEA.ORG.BR>. Acesso em: 12 abr. 2012.

CHARAUDEAU, Patrick. Discurso das mídias. São Paulo: Contexto, 2009a. 
Linguagem e discurso: modos de organização. Coord. Trad. Angela M. S. Corrêa e Ida Lúcia Machado. São Paulo: Contexto, 2009b.

IGREJA APOCALÍPTICA DO OITAVO DIA. Disponível em: <https://www.facebook.com/IgrejaApocaliptica>. Acesso em: 12 abr. 2012.

MAINGUENEAU, Dominique. Cena de enunciação. In: CHARAUDEAU, Patrick; MAINGUENEAU, Dominique. Dicionário de Análise do Discurso. Tradução de Fabiana Komesu. 2. ed. São Paulo: Contexto, 2008a. p. 95-97.

. Ethos, cenografia, incorporação. In: AMOSSY, R. (Org.). Imagens de si no discurso. São Paulo: Contexto, 2008b. p. 69-92.

A noção de ethos discursivo. In: MOTTA et al. (Orgs.). Ethos discursivo. São Paulo: Contexto, 2008c. p. 11-29.

VALENTE, André Crim. Descrição e Ensino do Português: sentidos da língua e do discurso na linguagem midiática. In: II FÓRUM DE ANÁLISE DO DISCURSO, 2010, Rio de Janeiro. Anais. Rio de Janeiro: UFRJ, 2010, p. 168-177.

Enviado em dezembro de 2012.

Aceito em dezembro de 2012. 